\title{
Research Paper: The Status of Posttraumatic Growth in Earthquake Survivors, Three Years After the Earthquake in East Azerbaijan
}

\author{
Mustafa Mardani ${ }^{1}$, Fardin Alipour ${ }^{1 *}$, Ramezanali Qaderi ${ }^{1}$, Mohammad Sabzi Khoshnam
}

1. Department of Social Work, University of Social Welfare and Rehabilitation Sciences, Tehran, Iran.

\begin{tabular}{c|c|}
\hline $\begin{array}{c}\text { Use your device to san } \\
\text { and read the article online }\end{array}$ \\
Crtation: Mardani M, Alipour F, Qaderi R, Sabzi Khoshnam M. The Status of Posttraumatic Growth in Earthquake Survivors, \\
Three Years After the Earthquake in East Azerbaijan. Health in Emergencies and Disasters Quarterly. 2017; 2(3):155-160. https:// \\
doi.org/10.18869/nrip.hdq.2.3.155 \\
doi: : https://doi.org/10.18869/nrip.hdq.2.3.155
\end{tabular}

Article info:

Received: 14 Oct. 2016

Accepted: 01 Feb. 2017

\section{Keywords:}

Disasters, Posttraumatic growth, Earthquake, East Azerbaijan

\begin{abstract}
Background: Experience of difficult incidents, besides its negative and adverse consequences, can have positive consequences and lead to the growth of people in several areas. Evaluating the status of posttraumatic growth in earthquake survivors could help better understand the various dimensions of this incident. The present study aimed to evaluate the status of posttraumatic growth in East Azerbaijan earthquake survivors.
\end{abstract}

Materials and Methods: This study is a cross-sectional and descriptive-analytical research. The study population consisted of East Azerbaijan earthquake survivors and the study sample included 295 survivors randomly selected from those who were eligible for the study. The research tools were a demographic questionnaire and posttraumatic growth inventory.

Results: The mean (SD) age of the participants was 43(14.3) years, and 50.5\% of them were male. The mean (SD) of the posttraumatic growth score of the study sample was $48.25(21.18)$. The findings of this study showed that among posttraumatic growth dimensions, "spiritual changes" (11.11[5.1]) and "connecting with others" (4.9[2.3]) had the highest score, while the "new possibilities" got the lowest score (16.3[7.19]).

Conclusion: Posttraumatic growth issue requires further attention in the mental and social health policies. The study results indicate that despite the many problems that the earthquake creates for people, dealing with this disaster leads to positive psychological effects on people, too.

\section{Introduction \\ I \\ ran as a disaster-prone country is one of the most susceptible regions in the world for various disasters and at risk of many threats. Iran is among the world's top 10 disaster- prone countries and $90 \%$ of its population} are exposed to the risks of earthquakes and floods. Also,
Iran is the fourth in Asia and sixth in the world in terms of natural disasters. Iran's vulnerability to earthquake is 1000 times greater than America and 100 times more than Japan. Earthquake, flood, and drought are the most common disasters in Iran to the extent that about $93 \%$ of Iran are prone to earthquake [1]. People may face with different disasters and incidents, including earthquake during their lives which have different consequences on them [2].

\section{* Corresponding Author:}

Fardin Ali Pour, PhD

Address: Department of Social Work, University of Social Welfare and Rehabilitation Sciences, Tehran, Iran.

E-mail: barbodalipour@gmail.com 
Part of these consequences comprise mental disorders that may occur in the short- and long-term. The main focus on these negative aspects and consequences is posttraumatic stress and depression [3]. However, many researchers ask whether or not these disasters are also associated with positive effects. If so, it is an interesting topic to examine these positive impacts, analyze their related factors, and differences in various disasters.

Ferankle for the first time mentioned that stressful life events may lead to positive consequences. But only in recent years, researchers have systematically attempted to understand and review positive changes after the stressful events. These damaging or stressful events may act as facilitators for positive psychological and social changes. Tedeschi and Calhoun were among the first researchers who studied the concept of Posttraumatic Growth (PTG) and defined it as "subjective experience of positive psychological changes created by the individual due to deal with the highly challenging events in life, such as traumas, disasters, and stressful incidents" [4]. Experience of difficult events may lead to the growth of the individual in several areas, namely mental health [5], appreciation of life, new possibilities, personal strengths, new approaches and new directions in life, communication with others, and spiritual changes. It is to be noted that people report these positive changes as a direct result of the disaster [6]. We cannot be indifferent to the negative effects such as anxiety, anger, depression, and behavioral problems and ignore them, so it is important to pay attention to these factors in this study [7].

Growth and positive changes can be achieved by fighting a very stressful event, strengthening individuals, families and communities, discovering strengths and talents previously unrecognized, and also strengthening the relations. PTG is a global phenomenon that can change over time. However, it is still a matter of debate whether achieving growth is the result of fighting a very stressful and potentially damaging event, a response strategy, a personality trait, or the manifestation of a provable change [8]. In various studies, the role of different events, such as cancer, HIV, bereavement, accidents and disasters, rape, war, surgery, and diseases has been investigated in creating PTG [9].

By reviewing the literature, it can be seen that various studies have been conducted so far in the area of PTG looking for positive impacts of traumas on the people of which useful information can be extracted. In this regard, the studies of Zarina Akbar (2015) entitled "posttraumatic growth," [10], Zhibin Wu et al. research (2015) aiming to investigate the relationships between positive and negative changes and risk factors in the earthquake survivors over a year after the Wenchaun earthquake [11], the research by Xiao Zhou and Xinchun Wu (2015) aiming to assess the relationship between rumination, posttraumatic stress, and posttraumatic growth in Chinese adolescents after the earthquake [12], and Xiao Zhou (2009) [13] can be mentioned and their results all indicate different rates of PTG in earthquake survivors. Research has also shown that natural disasters (such as earthquake) compared to man-made disasters have left lower levels of negative impacts on the psychological and social health of the people [14]. This study has tried to be one of the few studies in Iran that evaluate the status of PTG three years after Azerbaijan earthquake.

\section{Materials and Methods}

This study was a cross-sectional and descriptive-analytical research. The study population consisted of East Azerbaijan earthquake survivors in 2016, i.e. 3 years after the earthquake, and the sample included 295 survivors randomly selected from those who were eligible for the study. The research tools were a demographic questionnaire and posttraumatic growth inventory. Demographic questionnaire was compiled by the researcher to assess demographic characteristics of survivors and consisted of 15 questions about the features such as gender, age, education level, income, marital status, defects, mental and social services received.

Posttraumatic Growth Inventory (PTGI) was designed by Tedeschi and Calhoun in 1996 to study the concept of PTG in the United States. This inventory has 21 items that evaluates 5 areas of psychological growth after confrontation with a traumatic stressor (new possibilities, communication with others, life appreciation, personal power, and spiritual changes). It is rated based on the 6-point Likert-type scale in which the score of 0 is assigned to the first item (No) and 1 to 5 are assigned to the second to sixth items; the total scores range from 0 to 105 and higher scores indicate more growth and vice versa. The psychometrics of this tool was carried out in 2013 by Heidarzadeh et al. on 402 patients with cancer referred to Imam Khomeini and Shohada-ye Tajrish Tehran hospitals, and then it is standardized for Iranian community [15]. The Cronbach $\alpha$ coefficient for the entire tool was 0.87 and its coefficients for main 5 -factor scale components were $0.57-0.77$ [4]. For data collection, the questionnaires were completed by patients after presence in the affected areas and justifying them why they do this study and gaining their consent. For data analysis, descriptive and inferential statistics were used. 


\section{Results}

The present study analyzed data of 295 survivors. The mean (SD) age of the participants in the research was 43(14.3) years and $146(49.5 \%)$ of whom were women and $149(50.5 \%)$ were men. The results showed that all study survivors the showed some degree of growth and the mean (SD) PTG score in the samples was 48.25(21.18). Also noteworthy is that among posttraumatic growth indexes, "spiritual changes" (11.11[5.1]) and "connecting with others" (4.9[2.3]) gained the highest score, while "new possibilities" got the lowest score (16.3[1.9]) (Table 1). In examining the relationship between some demographic characteristics and PTG, it was found that the marital status has a significant negative correlation with PTG and its two dimensions of "spiritual changes" and "communication with others" as well as "personal power" $(\mathrm{P}<0.05)$. There was no significant difference in the PTG score and its dimensions according to other demographic characteristics, including age, education, income, and gender (Table 2).

\section{Discussion}

The present study aimed to evaluate posttraumatic growth in Azerbaijan earthquake survivors 3 years after the disaster. In this study, various demographic variables were used to evaluate their relationship with PTG. The results of this change is a step toward clarifying the concept of PTG and its relationship with other variables. An advantage of this study is investigating the concept of PTG three years after the East Azerbaijan earthquake in affected areas for the first time. These areas include 15 stricken villages of East Azerbaijan Province. Based on study results, 3 years after the disaster the earthquake survivors reported some degree of PTG. The highest growth rates were in the dimensions of "spiritual changes" and "communication with others," while the lowest rate was in the dimension "new possibilities". According to the Iranian religious beliefs, people show the strongest growth in their spirituality when faced with events such as natural and man-made disasters, in a way that spiritual dimension won the highest score in an internal study by Heidarzadeh et al. aiming to assess PTG in cancerous patients in Tehran [15]. The results are also consistent with various foreign studies assessing the PTG of earthquake survivors; so that the results of all foreign studies aiming to evaluate and measure PTG in earthquake survivors suggest some degree of PTG. However, the differences in the study results relate to the review of predictor and effective variables in PTG after the incidence $[11-13,16]$.

In the present study, of various demographic variables only "marital status" has shown a significant correlation with PTG. It is while in other similar foreign studies, there was a significant relationship between PTG and different variables. Some of these studies showed that job satisfaction, high levels of income, suitable living conditions, and social protection are very important factors in both the incidence of PTG and traumatic stress mitigation. Also, some demographic variables such as gender, education level, and housing status were effective in PTG $[11,13]$. To explain this discrepancy, different study environment, sample size, and other variables such as quality of life and level of social protection can be mentioned that may affect this condition.

One-stage study of the PTG in earthquake survivors could be mentioned as one of the study limitations. Also, in the theory of Tedeschi and Calhoun, time has been mentioned as a key factor in the growth changes and the passage of time can make major changes in the individual after the incident [17]. However, different studies in other countries have been done on the PTG in earthquake survivors. In these studies, sometime after the

Table 1. The score of posttraumatic growth and its dimensions in the sample

\begin{tabular}{|ccccc}
\hline Dimension & Min & Max & Mean (SD) & $\begin{array}{c}\text { The Average Score for Each Dimension } \\
\text { (0-5) }\end{array}$ \\
\hline New possibilities & 0 & 25 & $16.3(7.19)$ & 2.22 \\
\hline Communication with others & 5 & 35 & $11.11(5.14)$ & 2.32 \\
\hline Personal power & 0 & 20 & $9.19(4.2)$ & 2.29 \\
\hline Life appreciation & 0 & 15 & $6.7(3.1)$ & 2.24 \\
\hline Spiritual changes & 0 & 10 & $4.9(2.3)$ & 2.45 \\
\hline Total score of posttraumatic growth & 25 & 105 & $48.25(21.18)$ & 2.29 \\
\hline & & & & $\begin{array}{c}\text { Illealth in } \\
\text { Emergencies and lDisasters [Oluarterly }\end{array}$
\end{tabular}


Table 2. The relationship between demographic characteristics and posttraumatic growth of the sample

\begin{tabular}{|c|c|c|c|c|c|}
\hline \multicolumn{2}{|c|}{ Demographic Characteristics } & \multirow{2}{*}{$\begin{array}{c}\text { Number } \\
146\end{array}$} & \multirow{2}{*}{$\begin{array}{c}\text { Mean (SD) } \\
47.75(21.44)\end{array}$} & \multirow{4}{*}{$\begin{array}{c}\text { Test, a Significance Level } \\
\text { Independent T-Test }\end{array}$} & \multirow{4}{*}{$\begin{array}{l}\text { Sig. } \\
0.71\end{array}$} \\
\hline & Female & & & & \\
\hline Gender & & & & & \\
\hline & Male & 149 & $48.74(20.98)$ & & \\
\hline \multirow{5}{*}{ Marital status } & Married & 217 & $49.9(21)$ & \multirow{5}{*}{ ANOVA Test } & \multirow{5}{*}{0.03} \\
\hline & Divorced & 6 & $50.66(8.16)$ & & \\
\hline & & & & & \\
\hline & Widowed & 24 & $48.25(20.1)$ & & \\
\hline & Single & 48 & $40.27(22.24)$ & & \\
\hline \multirow{8}{*}{$\begin{array}{l}\text { Education } \\
\text { degree }\end{array}$} & Illiterate & 81 & $48.01(22.4)$ & \multirow{8}{*}{ ANOVA Test } & \multirow{8}{*}{0.2} \\
\hline & Primary & 65 & $48.38(18.93)$ & & \\
\hline & High school & 32 & $44.34(20.17)$ & & \\
\hline & Diploma & 47 & $46.57(23.2)$ & & \\
\hline & Associate degree & 11 & $60.81(12.29)$ & & \\
\hline & Bachelor & 51 & 49.92(21.63) & & \\
\hline & MA & 7 & $42.42(21.55)$ & & \\
\hline & $\mathrm{PhD}$ & 1 & 81 & & \\
\hline \multirow{5}{*}{ Income status } & No income & 81 & $45.2(21.2)$ & \multirow{5}{*}{ ANOVA Test } & \multirow{5}{*}{0.44} \\
\hline & Less than 1 million & 107 & 48.97(19.37) & & \\
\hline & & & & & \\
\hline & Between 1 and 2 million & 96 & $50.22(23.07)$ & & \\
\hline & More than 2 million & 11 & 46.09(20.96) & & \\
\hline
\end{tabular}

initial assessment, another evaluation was carried out to determine the role of disaster in PTG and also examine the passage of time as an essential factor in this matter. One of these studies is a research by Zarina Akbar [10] (2015) entitled "posttraumatic growth" and aimed to examine long-term psychiatric conditions among the earthquake survivors in Indonesia. In this study, there were 200 survivors of which 100 persons were affected and 100 others were not. The study results indicated that by passing each year from the incidence, survivors reported higher level of PTG after the incidence [10].

Based on several studies conducted abroad, a direct relationship exists between the passage of time after the incident and high scores of PTG $[12,16]$. As a result, it is suggested that the passage of time be considered as an important variable in future studies aiming to assess PTG. Also, after the initial assessment, another evalua- tion should be performed to determine the role of time in the growth of people.

This study has been carried out with the aim of considering positive factors of natural disasters, so that the researchers would not only consider the negative role of disasters but also take into account its growth factors.

Studying other variables such as social support, coping skills, and other associated items with PTG can help us to better understand and more accurately evaluate it. In this context, it is recommended to use the plans and methods stronger than correlational and cross-sectional methods in future works. The present study examined PTG in earthquake survivors for the first time in Iran to clarify the concept of PTG and its dimensions in addition to taking an important step towards providing better 
professional services in accordance with the conditions of the survivors.

Considering the relatively long period of psychological and social rehabilitation after incidents and disasters in Iran, social workers as the social rehabilitation team members are able to consider the PTG and its capacities in different interventions for providing better social and psychological services and facilitating the survivors's return to normal life. Also, identifying these capacities allows the design of social work interventions (individual, group, and society) to facilitate and foster the phenomenon of PTG for survivors of the disaster. In some social work approaches, including strengths-based approach that mainly focuses on individual abilities, it is possible to use the present research results so that not only the difference in negative impacts of the incident are determined, but also the growth rates and positive outcomes are studied and specialized services are provided according to their circumstances and strengths.

\section{Conclusion}

By comparing the study results in different countries with the current study, we can conclude that after an incident, people report different extent of growth in various aspects. It is noteworthy that the extent of growth could be affected by different factors like the severity of the incident, the degree of social support, people's response skills, religious beliefs, and so on.

The most important point is attention to long-term consequences of incidents like earthquake on people. Also sole attention on negative effects of the incidents and ignoring positive effects of incidents on people could postpone the recovery process of people to their normal lives. Therefore, the positive and developmental view toward rehabilitation period after incidents like earthquake could play an important and affective role in this regard.

\section{Acknowledgements}

This research did not receive any specific grant from funding agencies in the public, commercial, or not-forprofit sectors.

\section{Conflict of Interest}

The authors declared no Conflicts of Interest.

\section{References}

[1] United Nations Office For Disaster Risk Reduction. Living with risk. A global review of disaster reduction initiatives. Geneva: United Nations; 2002.

[2] Alipour F, Khankeh H, Sabzi M, Ahmadi S, Malmir I. Psychosocial rehabilitation: Some lessons learned from natural disaster in Iran. Health in Emergencies and Disasters. 2016; 1(2):105-10.

[3] Seyed Mahmoudi SJ, Rahimi Ch, Mohammadi N, Hadian Fard H. [Increased post traumatic growth over time and its relationship with coping styles and optimism in people with HIV-positive (Persian)]. Journal of Psychology Achievements. 2013; 4(2):165-86.

[4] Heidarzadeh M, Rassouli M, Mohammadi Shahbolaghi F, Alavi Majd H, Mirzaee HR, Tahmasebi M. [Validation of the Persian version of the posttraumatic growth inventory in patients with cancer (Persian)]. Payesh. 2015; 14(4):467-73.

[5] Rafiey H, Alipour F, Salimi Y, Ahmadi S, Mardani M, Sayad M. [Positive mental health three years after east Azerbaijan earthquake: A comparative study (Persian)]. Health in Emergencies and Disasters. 2017; 2(1):33-8.

[6] Alipour F, Khankeh H, Fekrazad H, Kamali M, Rafiey H, Ahmadi S. Social issues and post-disaster recovery: A qualitative study in an Iranian context. International Social Work. 2015; 58(5):689-703. doi: 10.1177/0020872815584426

[7] Askari A, Rowell RK, Alipour F. Prevalence of psychopathology and socio-demographic characteristics among earthquake survivors in Eastern Azerbaijan, Iran. Health in Emergencies and Disasters. 2015; 1(1):9-15.

[8] Weiss T, Berger R. Posttraumatic growth and culturally competent practice. New Jersey: John Wiley \& Sons; 2010. doi $10.1002 / 9781118270028$.

[9] Tennen H, Affleck G, Urrows S, Higgins P, Mendola R. Perceiving control, construing benefits, and daily processes in rheumatoid arthritis. Canadian Journal of Behavioural Science. 1992; 24(2):186-203. doi: 10.1037/h0078709

[10] Akbar Z. Post-traumatic growth: Long term psychological conditions among disaster survivors in Yogyakarta-Indonesia [PhD dissertation]. Leipzig: Leipzig University; 2015.

[11] Wu Z, Xu J, Sui Y. Posttraumatic stress disorder and posttraumatic growth coexistence and the risk factors in Wenchuan earthquake survivors. Psychiatry Research. 2016; 237:49-54. doi: 10.1016/j.psychres.2016.01.041

[12] Zhou X, Wu X, Chen J. Longitudinal linkages between posttraumatic stress disorder and posttraumatic growth in adolescent survivors following the Wenchuan earthquake in China: A three-wave, cross-lagged study. Psychiatry Research. 2015; 228(1):107-11. doi: 10.1016/j.psychres.2015.04.024

[13] Xu J, Wu W. Work satisfaction and posttraumatic growth 1 year after the 2008 Wenchuan earthquake: The perceived stress as a moderating factor. Archives of Psychiatric Nursing. 2014; 28(3):206-11. doi: 10.1016/j.apnu.2013.12.006.

[14] Berger, R. Stress, trauma, and post traumatic growth: Social context, environment, and identities. Abingdon: Routledge; 2015. doi: $10.4324 / 9780203118795$ 
[15] Heidarzadeh M, Rassouli M, Shahbolaghi F, Alavi Majd H, Mirzaei H, Tahmasebi M. [Assessing dimensions of posttraumatic growth of cancer in survived patients (Persian). Journal of Holistic Nursing and Midwifery. 2015; 25(2):33-41

[16] Zhou X, Wu X. The relationship between rumination, posttraumatic stress disorder, and posttraumatic growth among Chinese adolescents after earthquake: A longitudinal study. Journal of Affective Disorders. 2016; 193:242-8. doi: 10.1016/j. jad.2015.12.076

[17] Tedeschi RG, Calhoun LG. Posttraumatic growth: Conceptual foundations and empirical evidence. Psychological Inquiry. 2004; 15(1):1-18. doi: 10.1207/s15327965pli1501_01 